\title{
The influence of political ideology on DIT scores: fact or artifact?
}

\author{
Richard A. Bernardi \\ David F. Bean \\ Dawn W. Massey \\ Fairfield University, dmassey@fairfield.edu
}

Follow this and additional works at: https://digitalcommons.fairfield.edu/business-facultypubs Copyright 2004 Emerald

\section{Peer Reviewed}

\section{Repository Citation}

Bernardi, Richard A.; Bean, David F.; and Massey, Dawn W., "The influence of political ideology on DIT scores: fact or artifact?" (2004). Business Faculty Publications. 89.

https://digitalcommons.fairfield.edu/business-facultypubs/89

\section{Published Citation}

Richard A. Bernardi, David F. Bean and Dawn Massey. 2004. "The influence of political ideology on DIT scores: fact or artifact?" Research on Professional Responsibility and Ethics in Accounting, Volume 9, pp. 21-47.

This item has been accepted for inclusion in DigitalCommons@Fairfield by an authorized administrator of DigitalCommons@Fairfield. It is brought to you by DigitalCommons@Fairfield with permission from the rightsholder(s) and is protected by copyright and/or related rights. You are free to use this item in any way that is permitted by the copyright and related rights legislation that applies to your use. For other uses, you need to obtain permission from the rights-holder(s) directly, unless additional rights are indicated by a Creative Commons license in the record and/or on the work itself. For more information, please contact digitalcommons@fairfield.edu. 
THE INFLUENCE OF POLITICAL IDEOLOGY ON DIT SCORES:

FACT OR ARTIFACT?

\author{
Richard A. Bernardi*1 \\ Professor \\ Gabelli School of Business \\ Roger Williams University \\ Telephone: (401) 254-3672 \\ FAX: (401) 254-3545 \\ Email: rbernardi@rwu.edu
}

\title{
David F. Bean
}

Associate Professor

Hagan School of Business

Iona College

New Rochelle, NY 10801-1890

Telephone: (914) 633-2267

FAX: (914) 633-2012

Email: dbean@iona.edu

Dawn W. Massey

Assistant Professor

Charles F. Dolan School of Business

Fairfield University

Fairfield, CT 06824-5195

Telephone: (203) 254-4000 x2844

FAX: (203) 254-4105

Email: dmassey@mail.fairfield.edu 


\title{
Political Ideology On DIT Scores
}

\begin{abstract}
Concern about the validity of the DIT and Fisher and Sweeney's measurement of conservative, moderate and liberal political orientation using a seven-point Likert scale motivates our study. We perform two experiments to investigate these interrelated issues. First, we assess the degree to which 569 undergraduate students' political orientation as measured by a seven-point Likert scale associates with their corresponding political orientation as measured by a ninepoint Likert scale. We find differences in categorization of subjects depending upon scale used, suggesting problems with the sampling distribution arise when a seven-point Likert scale is used for categorizing subjects. Second, we measure 115 students' political orientation utilizing a nine-point Likert scale to assess Fisher and Sweeney's findings. Our results suggest that Fisher and Sweeney's findings may relate to their using a seven-point Likert scale in measuring political orientation rather than a flaw in the DIT's validity resulting from an embedded political ideology.
\end{abstract}




\section{THE INFLUENCE OF POLITICAL IDEOLOGY ON DIT SCORES:}

\section{FACT OR ARTIFACT?}

In recent years, a plethora of ethics research in accounting has used Rest's (1979) Defining Issues Test (DIT) as a measurement instrument (e.g., Louwers et al., 1997). This increase is not only due to an increased emphasis on ethics as an important consideration in accounting research, but also is due to an increase in the number of Ph.D. graduates writing dissertations investigating various aspects of accounting ethics (e.g., Ponemon, 1988; Bernardi, 1991; Massey, 1997; Thorne, 1997). Although these accounting-ethics researchers studied various issues, a common thread in the research is their use of the DIT. For instance, Ponemon examined the average level of moral development (as measured by the DIT) by staff level in public accounting. Bernardi found that high-moral development (as assessed using the DIT) managers detected fraud at a significantly higher rate when they were provided with information concerning client integrity ratings. Massey and Thorne both developed tests of moral reasoning based on the Defining Issues Tests that used auditing-based ethical dilemmas.

Despite widespread use of the DIT, some researchers have questioned its validity. For instance, Gilligan (1982) voiced concern about the DIT, maintaining that it favored (opposed) the male (female) justice- (care-) oriented reasoning. Interestingly, Bernardi and Arnold (1997) find that, rather than scoring lower than 
men, women actually scored significantly higher than men on the DIT. Bernardi and Arnold note that Gilligan's results may have resulted from sampling bias since her sample only consisted of 32 subjects divided into eight groups of four (two men and two women).

Fisher and Sweeney (2001: 3) question the continued use of the DIT, because research to date provides only "relatively modest relationships found between moral reasoning of accountants . . . and professional judgments and behavior." Perhaps a more cogent argument would be that the DIT uses generic ethical dilemmas and that the use of auditing-based ethical dilemmas (Massey, 1997; Thorne, 1997) might provide clearer results. Nonetheless, Fisher and Sweeney's (2001) argument continues that scores on the DIT “favor those with political liberalism to political conservatism" (p. 3).

We use two experiments to examine: (1) the appropriateness of using a seven-point Likert scale to assess the three categories of political orientation (i.e., conservative, moderate, liberal); and (2) whether Fisher and Sweeney (1998) findings are robust if one uses a sample distribution derived from a nine-point Likert scale. Our analysis indicates that Fisher and Sweeney's findings are not supported by an evenly distributed nine-point scale. Our findings do not change when we segment our nine-point data using Fisher and Sweeney's argument that only those selecting the middle value (i.e., five on a nine-point scale) are 
moderates, which calls into question findings using Fisher and Sweeney’s application of their seven-point scale.

\section{THEORETICAL BACKGROUND AND LITERATURE REVIEW}

\section{Moral Development}

We can partially describe the cognitive-developmental theory of moral development (Kohlberg, 1979) using four characteristics: cognitive, structural, developmental and sequential. First, the cognitive-developmental theory of moral development maintains that cognition is an integral part of the ethical decision process. Second, cognitive structures provide a framework for moral reasoning comprising six stages over three levels. Third, moral development is a cognitive process that develops over time. Fourth, the developmental process is sequential because moral reasoning progresses in one direction only (Ponemon and Gabhart, 1993; Rest and Narváez, 1994). That is, while individuals may progress to higher levels of moral reasoning structures over time, they cannot regress.

Rest and Narváez (1994) describe this process of moral development using a staircase as an example. Increases in moral reasoning are likened to an individual climbing a staircase; development (climbing the staircase) occurs in discrete steps. According to this developmental perspective, how morality is perceived is a function of an individual's level of moral reasoning (Kohlberg, 1958, 1979). The three levels of Kohlberg's moral reasoning are: preconventional, conventional, and post-conventional or principled. 
Individuals at the two stages of the pre-conventional level assess the moral acceptability of alternative ways to resolve a moral dilemma by the rewards and punishments they attach to various outcome choices. Individuals at the two stages of the conventional level determine the moral acceptability of alternate ways to resolve a moral dilemma through their interpretation of group norms. Individuals at the two stages of the post-conventional or principled level utilize complex notions of universal fairness and an internal sense of responsibility and justice to define the moral acceptability of alternate ways to resolve a moral dilemma.

\section{Measuring Moral Development Using the DIT}

The DIT is a psychometric instrument used to assess moral reasoning. It appears often in psychology and social science studies (Rest, 1986; Rest et al., 1999). Accounting ethics researchers also commonly use the DIT (Louwers, et al., 1997). However, some criticize accounting ethics researchers' use of the DIT because of the DIT's inability to aid in assessing moral behavior (e.g., Thornton, 2000: 241-244). Nonetheless, even Thornton (2000: 244) concedes, "Despite these criticisms, the DIT is an excellent measurement instrument that describes how the accounting profession makes cognitive moral judgments.” Indeed, prior researchers have found that the DIT generally displays adequate validity (construct validity, content validity, and empirical validity) and reliability 
(temporal stability, internal consistency, and immunity from artificial score inflation).

Because the DIT is based on Kohlberg's $(1969,1979)$ cognitive theory of moral development, it has construct validity (Frankfort-Nachmias and Nachmias, 1992). Additionally, the DIT exhibits both elements of content validity: face validity and sampling validity (Frankfort-Nachmias and Nachmias, 1992). With respect to face validity, Rest et al. (1974) report that 65.2 percent of doctoral students in moral philosophy and political science attained scores on the DIT in the post-conventional or principled range while only 50.4 percent of college students attained scores on the DIT in the post-conventional or principled range. Thus, it appears that the test is, indeed, capturing a cognitive skill more closely associated with moral philosophy and political science Ph.D. students than college students. Sampling validity (Frankfort-Nachmias and Nachmias, 1992) of the DIT is underscored by results in Alozie (1976). In Alozie's (1976) study, subjects' DIT scores correlated (at $r=.75$ ) to their scores on a similar test developed by Kohlberg (the Moral Judgment Interview). Finally, as a measure of a cognitive ability, the DIT also exhibits empirical validity (Frankfort-Nachmias and Nachmias, 1992) through its correlation with education (e.g., Dortzbach, 1975). Davison and Robbins's (1978) review of several studies establishes for the DIT two measures of reliability: temporal stability and internal consistency (Frankfort-Nachmias and Nachmias, 1992). According to Davison and Robbins 
(1978), the test-retest reliability of scores on the DIT is generally in the high .70s or .80s. Similarly, Davison and Robbins (1978) find that internal consistency of the DIT (as measured by Cronbach's alpha) is in the upper .70s.

Finally, McGeorge (1975) establishes that the DIT is immune to artificial score inflation. In McGeorge's experiment, three groups of subjects completed the DIT twice. In a fully randomized design, each of the groups completed the DIT once with ordinary instructions. In the control group, the other completion of the DIT was also according to the original instructions. In the experimental group, McGeorge asked subjects to "fake" (either good or bad) on their other completion of the DIT. Importantly, although McGeorge found subjects' DIT scores were significantly lower in the "fake bad" conditions (regardless of whether they were in the ordinary-bad or bad-ordinary group), he found no significant differences in DIT scores for any other condition. Thus, DIT scores can be "faked downward" but not "faked upward". Accordingly, McGeorge's results confirm a primary assumption of moral development theory: an individual at a given stage of moral development is incapable of understanding higher order moral arguments. That is, an individual can lower his/her score on the DIT by identifying lower order responses but should not be able to identify higher order responses as the higher order responses are beyond the individual's cognitive capacity. 


\section{Political Ideology and the DIT - the Current Debate}

Despite studies suggesting the validity and reliability of the DIT (as

described above), some researchers question the validity of the DIT and believe that the DIT produces a measure of moral reasoning that is biased by political orientation. Emler et al. (1983) assert that the DIT score is a measure of political attitude. Fisher and Sweeney (2001) suggest that the DIT has an underlying political content that over- (or under-) states an individual's true capacity for moral reasoning. This may cause an individual to consciously or unconsciously reject more advanced responses even though the individual understands the underlying moral reasoning. Fisher and Sweeney (2001: 7) argue that [I]f a politically conservative person comprehends the cognitive complexity of principled DIT responses and chooses to avoid ranking those responses as important because he or she associates this viewpoint with liberalism, then the P score would not be measuring this person's most advanced moral thinking....

Similarly, a politically liberal test-taker may overstate his or her DIT P score by ranking higher-order response items as important because of their association with liberal ideology, without comprehending the underlying moral content. 


\section{Fisher and Sweeney's Studies}

To empirically assess whether the DIT has an underlying political content that masks moral reasoning, Fisher and Sweeney conduct three studies: Fisher and Sweeney (1998), Sweeney and Fisher (1999), and Fisher and Sweeney (2001). In the first study, Fisher and Sweeney (1998) used 112 undergraduate accounting majors as experimental subjects. Subjects first responded to the DIT, a National Election Survey (see National Election Studies, 2002, for the most recent version) and also indicated on a seven-point scale how liberal or conservative they were concerning important political and social issues. The authors then coded subjects' responses to the seven-point scale as follows: subjects choosing 1-3 were coded as political liberals, subjects choosing 4 were coded as political moderates, and subjects choosing 5-7 were coded as political conservatives.

After a two-week period, Fisher and Sweeney randomly assigned subjects to groups who were asked to complete the DIT from either: the perspective of an "extremely conservative" person or the perspective of an "extremely liberal" person. Subjects in Fisher and Sweeney's study decreased their P scores by responding to the DIT from an "extremely conservative" perspective and increased their P scores by responding to the DIT from an "extremely liberal" perspective. Accordingly, Fisher and Sweeney suggest that some items in the DIT may have a political content separate from their contribution to the assessment of moral reasoning. 
In the second study, Sweeney and Fisher (1999) replicate the first study using a subject pool of 137 undergraduate accounting majors. Notably, they conducted the same within-subjects design experiment, using the same sevenpoint scale to classify subjects as politically liberal, politically moderate or politically conservative as in Fisher and Sweeney (1998). Not surprisingly, Sweeney and Fisher's (1999) findings are strikingly similar to those in Fisher and Sweeney (1998). ${ }^{2}$

In the third study, Fisher and Sweeney (2001) used 221 undergraduate accounting majors from two midwestern universities as experimental subjects. They utilized a between-subjects design and randomly assigned subjects to either the control or experimental condition. Both groups of subjects completed the DIT. The control group completed the DIT under standard test instructions (see http://www.coled.umn.edu/CSED/). In the experimental group, Fisher and Sweeney (2001: 13) provided subjects with modified instructions informing them that:

The Defining Issues Test is a standardized measure of moral judgment. We are interested in whether you can identify the statements designed to represent the highest level of moral judgment. 
Subjects in the 2001 study also indicated on a seven-point scale how liberal or conservative they were concerning important political and social issues. Subjects' responses to the seven-point scale served as the basis for classifying subjects as liberal (those who chose 1-3 on the scale), moderate (those who chose 4 on the scale) or conservative (those who chose 5-7 on the scale).

The experimental results show that, for liberals, the mean DIT P score was significantly lower $(\mathrm{p}<.10)$ under the modified instructions than under the standard instructions. For moderates, there were no significant differences according to the instructions the subjects received. For conservatives, the mean DIT P score was significantly higher $(\mathrm{p}<.05)$ under the modified instructions than under the standard instructions. Based on their results, Fisher and Sweeney (2001) conclude that the DIT systematically overstates (understates) the moral reasoning abilities of political liberals (conservatives).

Further, when subjects received standard instructions, Fisher and Sweeney (2001) found a significantly higher $(\mathrm{p}<.001)$ mean $\mathrm{P}$ score for liberals than the mean $\mathrm{P}$ scores for moderates and conservatives. In contrast, when subjects received the modified instructions, their mean $\mathrm{P}$ scores did not differ by political ideology $(p=.920)$. These results lead Fisher and Sweeney (2001) to suggest that instructions to the DIT may be causing subjects to pursue DIT statements consistent with their preferred political ideology, preventing the instrument from presenting a true measure of the person's moral competence. 
If true, the results from much of the ethics based research utilizing the DIT are questionable and this body of research becomes extremely difficult to assess and interpret. However, we have great concern about the methodology employed in Fisher and Sweeney's studies. In particular, we take exception to Fisher and Sweeney's use of a seven-point Likert scale that is unevenly apportioned to classify subjects as liberal, moderate, or conservative (i.e., 1-to-3 are for conservative, 4 is moderate, and 5-to-7 are for liberal). While this methodology is convenient and provides an approximately equal distribution between liberals, moderates, and conservatives in Fisher and Sweeney's studies, we believe it is inappropriate to assign only one data point to the moderate classification and three each to the liberal and conservative classifications. Indeed, according to Siegel and Castellan (1988: 24),

In a nominal scale, the scaling operations partition a given class into a set of mutually exclusive subclasses. The only relation involved is that of equivalence; that is, the members of any one subclass must be equivalent in the property being scaled. (Emphasis in the original.)

In classifying subjects as political liberals, conservatives and moderates (i.e., nominal classifications), Fisher and Sweeney give three choices on their 
scale for political liberals as well as for political conservatives, but only one choice for political moderates. As a result, Fisher and Sweeney's classification scheme is inconsistent with Siegel and Castellan's basic requirement for subclass equivalence in nominal classification. Accordingly, to achieve subclass equivalence (Siegel and Castellan, 1988), a better measure for classifying subjects as political liberals, moderates and conservatives might derive from a nine-point scale that is evenly apportioned when assigning subjects to categories. Such an expanded scale provides an equal number of choices for each of the three nominal classifications.

Given Fisher and Sweeney's research and our concern about their basic methodology for determining political orientation, we propose to test first whether political orientation classification differences result from using a seven-point versus a nine-point scale. The hypothesis to test this assertion follows:

H1: Differences in classification of subjects as political conservatives, moderates and liberals will arise from basing the classification on a seven-point scale that is unevenly apportioned to classify subjects (as in Fisher and Sweeney, 1998, 2001) as opposed to basing the classification on a ninepoint scale that is evenly apportioned to classify subjects.

In anticipation of differences in the classification of subjects as political conservatives, moderates and liberals emerging from use of the nine- versus 
seven-point scale (i.e., if we find support for H1), we also undertake a second experiment to replicate Fisher and Sweeney's studies - using political classifications based on responses to a nine-point scale that is evenly apportioned - to test the same three hypotheses that they used in their research (Fisher and Sweeney, 1998, 2001):

H2a: Accounting students with a liberal political identification will attain higher DIT P scores, on average, than accounting students who are not liberal.

H2b: Accounting students who are not politically conservative will decrease their DIT $P$ scores when responding from a conservative perspective.

H2c: Accounting students who are not politically liberal will increase their DIT P scores when responding from a liberal perspective.

\section{EXPERIMENT ONE: SUBJECTS, MEASURES AND RESULTS}

\section{Sample}

Five hundred and sixty-nine students enrolled in accounting classes at three private institutions in the Northeast participated in the first experiment. All provided usable responses. On average, approximately 50 percent of the students are female, and their mean age is 19.6. 


\section{Political Attitudes Survey}

Subjects completed a political attitudes survey (See Appendix A). The first three questions (Appendix A, items a to c) on the political attitudes survey are drawn from the National Election Studies (NES) (NES, 2002) and ask subjects to indicate their opinions about three social and economic issues on a nine-point Likert scale (Appendix A, items a to c). Additionally, we asked subjects to indicate their political orientation on two scales: 1) the same seven-point scale Fisher and Sweeney $(1998,2001)$ used; and 2) a nine-point version of the scale Fisher and Sweeney $(1998,2001)$ used (See Appendix A, items d and e). Notably, one-half of the subjects in our study completed the seven-point political orientation scale first, followed by the nine-point version of the scale; the other half of the subjects in our study completed the nine-point scale first, followed by the seven-point scale.

To assess the validity and reliability of subjects' self-reported political orientation, we correlated participants' responses to the three social and economic issues drawn from the NES with both their political orientation indicated on the seven-point scale $(.345, \mathrm{p}<.001)$ and their political orientation indicated on the nine-point scale $(.366, \mathrm{p}<.001)$. Results of these correlations suggest the subjects' self-reported political orientations valid and reliable measurements for use in the study. 
Accordingly, we then use subjects' responses to the seven-point (ninepoint) political orientation scale to classify subjects as political liberals, moderates or conservatives according to the uneven (even) distributions in Fisher and Sweeney (the present study). Next, we compare subjects' assessed political orientation classifications, as derived from the seven- and nine-point scales so that we may test whether hypothesis 1 holds.

\section{Classification Differences (H1)}

Results

Table 1 maps and assesses subjects' categorization as liberals, moderates and conservatives according to Fisher and Sweeney's $(1998,2001)$ seven-point scale that is unevenly apportioned against subjects' categorization as liberals, moderates or conservatives political classifications based on responses to a nine-point scale that is evenly apportioned. Of the 209 students who indicated a liberal orientation on the seven-point scale, 94 (italicized values in Table 1) switched from a liberal to moderate orientation on the nine-point scale (i.e., 55 percent consistency). Of these 94, 74 (78 percent) switched from the 3 ranking on the seven-point scale to the 4 raking on the nine-point scale. Only ten of the original 207 moderates on the seven-point scale switched their political orientation on the nine-point scale (i.e., 94 percent consistency). Finally, of the 153 students who indicated a conservative orientation on the seven-point scale, 75 
(underlined values in Table 1) switched to a moderate orientation on the ninepoint scale (i.e., 51 percent consistency). Of these 75,59 (82 percent) switched from the 5 ranking on the seven-point scale to the 6 ranking on the nine-point scale.

\section{TABLE 1 ABOUT HERE}

When compared to a nine-point scale, the seven-point scale classifies more individuals as having liberal and conservative orientations and, at the same time, classifies fewer individuals as having a moderate orientation. That is, while the number of liberals (conservatives) decreased from 209 (153) to 122 (81), moderates increased by like amounts (i.e., $\underline{\underline{94}}$ for liberals and $\underline{75}$ for conservatives). Additionally, use of the seven-point scale results in a different classification for a small number of subjects (ten) as moderates when they are classified using the nine-point scale as either liberals $(n=7)$ or conservatives $(n=$

3). Thus, we would classify 31 percent of the subjects $([\underline{\underline{94}}+\underline{75}+10] / 569)$

differently using Fisher and Sweeney's (1998) unevenly apportioned scale as compared to classifications based on an evenly apportioned nine-point scale. As shown in Table 2, these differences are statistically significant $\left(X^{2}=29.5 ; \mathrm{p}<\right.$ $.001)$, suggesting that hypothesis 1 holds. 
Of the 207 participants who indicated a conservative political orientation on the seven-point scale, 155 (74.9 percent) expressed a political orientation of five (i.e., dead center) on the nine-point scale. However, we did not anticipate a change in the political orientations of these individuals; rather, we expected a change for individuals who indicated either of the adjoining preferences (i.e., three or five) on the seven-point scale. Of the 135 individuals who indicated three on the seven-point scale, $\underline{\underline{74}}(54.8$ percent) switched to a four (moderate political orientation) on the nine-point scale. Similarly, of the 99 individuals who indicated five on the seven point scale, $\underline{59}$ (59.6 percent) switched to a six (moderate political orientation) on the nine-point scale.

\section{TABLE 2 ABOUT HERE}

Moreover, as shown in Table 2, the percentage of subjects in this study that were categorized as political liberals, moderates or conservatives based on their responses to Fisher and Sweeney's seven-point, unevenly apportioned scale also differ from the percentage of subjects that Fisher and Sweeney (1998) categorized as political liberals, moderates or conservatives $($ chi squared $=16.2 ; \mathrm{p}$ $<.001)$. This finding suggests that beyond differences in subjects' classification according to scale used (i.e., seven- versus nine-point), fundamental differences between our sample and Fisher and Sweeney's (1998) also exist. These results 
reinforce the need to replicate Fisher and Sweeney's $(1998,2001)$ studies and reassess whether the hypotheses they propose are robust when classifying subjects as political liberals, moderates or conservatives according to a nine-point, evenly apportioned scale.

\section{NES and HERI Databases}

Part of the data in Table 3 is taken from the National Election Studies (NES) (2002), which represent the averages for a 28-year period (1972 to 2000). The NES data are from voter surveys taken before major elections (i.e., typically surveys of 45-year old American voters). The data represent a nine-point scale: (1) Extremely Liberal, (2) Liberal, (3) $\underline{\text { Slightly Liberal, (4) Moderate/Middle of }}$ the Road, (5) Slightly Conservative, (6) Conservative, and (7) Extremely Conservative (emphasis added). Of the remaining two points, " 8 " indicates "haven't thought much about this" and "0" (i.e., the ninth response) indicates "Don't know" (NES question G1a.T). These non-responses (i.e., selections of 8 and 0) represent approximately 29 percent of those surveyed during the 28 -year period. The data represent averages, which we standardized to 100 percent. 
Some of the data in Table 3 also comes from the Higher Education Research Institute (HERI) (2002): these data also represent the averages for the same 28-year period (1972 to 2000). The HERI data are from students about to enter their freshman year of college and represent the responses of "over 404,000 students [who] completed the Freshman Survey at 717 participating institutions nationwide" (HERI, 2002). HERI gathered its data on a five-point scale: (1) Far Left, (2) Liberal, (3) Middle-of-the-Road, (4) Conservative, and (5) Far Right (emphasis added). Because the data represent completed responses, we did not need to standardize the data. ${ }^{3}$

Experiment One finds that either political opinions are scale dependent or there may be differences between the populations in Fisher and Sweeney's (1998) sample and our sample. In Table 3, we group Fisher and Sweeney's data as well as our own data into three categories: liberal, moderate and conservative. For comparative purposes, we also group NES data and HERI data into the same three categories. Because NES derives its data from a seven-point scale, we use two methods to group the data. In Method One, which is consistent with Fisher and Sweeney's approach, we categorize only those from the middle designation on the seven-point NES scale, "moderate", as moderates. Using Method One, we categorize as liberals those who are "extremely liberal", "liberal", or "slightly liberal"; we categorize as conservatives those who are "extremely conservative", "conservative", or "slightly conservative". 
In Method Two, which is consistent with our approach, we categorize those who are in the three middle designations on the NES, "slightly liberal", "moderate", and "slightly conservative", as moderates. Using Method Two, we categorize as liberals those who are "extremely liberal" or "liberal"; we categorize as conservatives those who are "extremely conservative" or "conservative."

The HERI data come from a five-point scale. We group the HERI data into the three categories (liberal, moderate, and conservative) by including as moderates those HERI designates as "moderate." For categorizing the HERI data, we include as liberals those who are "far left" and "liberal"; conservatives are those who are "far right" and "conservative." Interestingly, the NES data, as grouped using Method Two, closely approximate the grouped HERI data. Accordingly, these two groupings may provide comparative benchmarks that are superior to the NES data, as grouped using Method One.

As shown in Table 3, Fisher and Sweeney's data, as grouped into liberal, moderate and conservative categories, closely approximate the data from the NES, as grouped into the same categories using Method One. In contrast, Fisher and Sweeney's data, as grouped into the three categories, closely approximates neither the data from NES, as grouped using Method Two, nor the grouped data from HERI.

Data from our nine-point scale, as grouped into liberal, moderate and conservative categories, are similar to both the NES data, as grouped using 
Method Two as well as the grouped HERI data. In fact, groupings of our data are within ten percentage points of HERI data in all categories.

These findings lead to two questions about Fisher and Sweeney's research. First, did Fisher and Sweeney use the most appropriate scale for comparison to their data? That is, are the political orientations of college seniors more closely aligned with those of the average 45-year-old American voter (i.e., NES data) or those of a college freshman (i.e., HERI data)? Second, why didn't Fisher and Sweeney attempt a bootstrap procedure - moving the two "slightly" categories in the NES data to the middle-of-the-road category (i.e., grouping the NES data using Method Two) - to assess the robustness of their results?

\section{EXPERIMENT TWO: SUBJECTS, MEASURES AND RESULTS}

In Experiment Two, as in Fisher and Sweeney's (1998, 2001) studies, subjects first responded to the DIT, a national election survey, and indicated their political orientation on a Likert scale. Different from Fisher and Sweeney's studies, however, subjects in our study utilized a nine-point, evenly apportioned scale to indicate their political orientation. Similar to Fisher and Sweeney (1998, 2001), within a three-week interval subjects complete the DIT a second time - but this time from either the perspective of an "extremely liberal" or "extremely conservative" person. Our research methodology controls for political orientation 
by assigning students to the three treatment groups based on the political orientation they indicated and their DIT P score.

\section{Sample}

One hundred and thirty-two freshman and sophomore business students enrolled in accounting classes at three private institutions in the Northeast provided complete responses to both parts of the experiment. Of the 132 students, we eliminated 17 (12.9 percent) because they failed the meaningless or consistency checks on the DIT. This left 115 students in the final sample. These students took the DIT twice during a two-to-three-week period.

\section{Political Attitudes Survey}

As in Experiment One, the students completed a political attitudes survey (See Appendix B). The first five questions (Appendix B, items a to e) on the political attitudes survey are drawn from the National Election Studies (NES, 2002) and ask subjects to indicate their opinions about social and economic issues on a nine-point Likert scale. Additionally, we asked subjects to indicate their political orientation on a nine-point, evenly apportioned version of the scale Fisher and Sweeney $(1998,2001)$ used. The participants' responses to the five social and economic issues drawn from the NES correlated $(.464, \mathrm{p}<.001)$ with their political orientation indicated on the nine-point scale, suggesting that 
subjects' self-reported political orientations are valid and reliable measures for use in Experiment Two. ${ }^{4}$

We then use subjects' responses to the nine-point political orientation scale to classify them as political liberals, moderates or conservatives. We use subjects' political orientation classifications, as derived from the nine-point scale, to assess whether hypotheses $2 \mathrm{a}, 2 \mathrm{~b}$ and $2 \mathrm{c}$ hold.

\section{Defining Issues Test}

We use the three-story version of the DIT to measure the subjects' moral development (Rest, 1979). ${ }^{5}$ The DIT presents subjects with three ethical dilemmas. Twelve considerations that reflect moral reasoning at the upper five stage levels of moral development follow each dilemma (i.e., the DIT does not include Stage One considerations). For each dilemma, the test directs individuals to first rate all twelve considerations (as having Great, Much, Some, Little or No importance to their resolution to the ethical dilemma) and then rank the four most important of the considerations for resolving the dilemma. We use subjects' rankings to determine DIT P scores - the percent of post-conventional or principled (i.e., Stage Five and Six) considerations a subject uses in resolving the three moral dilemmas. DIT P scores range from zero to 90; a score of zero (90) indicates that all ranked considerations are in the lower four (upper two) stage levels. 
Additionally, the DIT also assesses reliability of subject responses by providing "M" (for meaningless) scores and consistency checks. Because the "M" items are "written to sound lofty and pretentious but [are] not [intended] to mean anything" (Rest, 1979: 4), they screen for subjects who typically emphasize meaningless items in considering the ethical dilemmas and therefore lack the proper test-taking set. The DIT's consistency checks allow the researcher to screen for subjects who haphazardly respond to the instrument. Rest (1979: 7) reports that between five and fifteen percent of the sample is generally lost because subjects fail to pass the DIT's reliability checks.

\section{Political Identifications and DIT P Scores $(\mathrm{H} 2 a)$}

Results

Table 4 presents the DIT scores by political orientation for the sample of 115 students. In addition to providing the $\mathrm{P}$ scores, we also provide equivalent scores for stages three, four, five and six. For comparison, we also provide the average scores for Fisher and Sweeney's sample (1998) and the data from Rest's (1987) standardization sample. Hypothesis 2a tests whether accounting students with a liberal political identification will, on average, have a higher average DIT P score than accounting students who are not liberal in their political identification. Because political liberals in our study have a slightly lower DIT P 
score than political conservatives, it is evident that Hypothesis $2 \mathrm{a}$ is not supported by the data in Table 4 .

\section{TABLE 4 ABOUT HERE}

\section{Effect of College Level and Version of DIT}

The average DIT P score for the subjects in our study was significantly lower than both the average DIT P score Rest (1987) reports for a standardization sample of college graduates as well as the average DIT P score Fisher and Sweeney (1998) report for their sample of accounting students. Although interesting, these differences are not entirely unexpected given the subtle differences in the samples from which they are drawn (c.f., Bernardi and Arnold, 1997). That is, Rest's sample includes 270 college graduates with B.A. degrees, while Fisher and Sweeney limit their sample of 112 to junior and senior accounting majors at two schools. Our research includes 115 freshman and sophomore business students - from all majors - at three schools.

Rest's (1987: 3-13) data indicates that a 13.82-point difference exists between the DIT P scores of college graduates (44.85) and senior high school students (31.03). If one assumes a uniform increase, an individual's DIT P score should increase throughout their college experience at a rate of approximately 3.45 points per year (13.82/4). For instance, we would reduce Fisher and 
Sweeney's (1998) and Sweeney and Fisher's (1998) reported average P scores of 38.2 by $6.9(2 * 3.45)$ to 31.3 because college juniors and seniors make up their sample whereas college freshmen and sophomores make up our sample.

For those studies that used the six-story version of the DIT (i.e., Fisher and Sweeney, 1998; Sweeney and Fisher, 1998), a second adjustment must be made because the highest score on the six (three) story version is 95 (90). Thus, after adjusting for the six-story versions of the DIT, we would reduce Fisher and Sweeney’s (1998) and Sweeney and Fisher's (1998) projected P scores of 31.3 for freshmen and sophomores to $29.7(31.3 *$ [90/95]). Consequently, the average P score of 27.4 reported in this research is not substantially different than that reported in Fisher and Sweeney's (1998) and Sweeney and Fisher's (1998) when adjusted for a freshman and sophomore sample and the version of the DIT we used in the present research. Other differences in the DIT scores could arise from differences in school type (i.e., public versus private).

\section{Political Perspectives and Changes in DIT P Scores (H2b \& H2c) Results}

The data in Panel A of Table 5 provide the two sets of average scores for each manipulation of political perspective: (1) scores based on subjects responses to the DIT according to ordinary instructions (denoted "SelfPresentation"); and (2) scores based on subjects responses to the DIT according to 
instructions to respond from either an "Extremely Liberal Perspective" or an "Extremely Conservative Perspective." The proportions of subjects for each political orientation in our sample approximate those for college freshmen, which are drawn from HERI (2002) and reported in Table 3: liberals are 19.1 percent in this study versus 24.7 percent according to HERI data appearing in Table 3; moderates are 50.4 percent (this study) versus 54.6 percent (HERI data); conservatives are 30.5 percent (this study) versus 20.7 percent (HERI data). Hypothesis $2 \mathrm{~b}$ examines whether accounting students who are $\underline{\text { not }}$ politically conservative will decrease their DIT P scores when responding from a conservative perspective. The data in Table 5 indicate that, rather than decreasing, there was a slight increase in P scores for both of the groups who were not conservative and who were told to respond from a conservative perspective; however, these increases were not significant.

\section{TABLE 5 ABOUT HERE}

Hypothesis 2c examines whether accounting students who are $\underline{\text { not }}$ politically liberal will increase their DIT P scores when responding from a liberal perspective. The data in Table 5 indicate that the $\mathrm{P}$ scores for conservatives who were told to respond from a liberal perspective follow the anticipated direction for Hypothesis $2 \mathrm{c}$ in that they increased. However, the increase was slight and 
therefore not statistically significant. On the other hand, the average DIT P score for moderates who were told to respond from a liberal perspective actually decreased; but, again, the difference was not significant. ${ }^{6}$

Nine Versus Seven Point Results

The data in Panel A of Table 5 use our nine-point scale to split our sample into three evenly apportioned groups (i.e., 1-to-3 for liberals, 4-to-6 for moderates, and 7-to-9 for conservatives). An accepted procedure to test the effect choice of cutoff point has on the outcome of tests (i.e., to assess the robustness of the findings) is to move those individuals who are adjacent to a cutoff point from one grouping to another. In this case, we assess the effect of our choosing cutoff points based on three evenly apportioned groups by also choosing cutoff points using the procedure that Fisher and Sweeney advocate $(1998,2001)$ (i.e., including only those selecting the middle value, 5, as moderates and including those selecting 1-to-4 as liberals and those selecting 6-to-9 as conservatives).

By redistributing subjects according to the cutoff points Fisher and Sweeney advocated in their studies, the proportion of subjects in our study included in each category of political orientation more closely approximate those in Fisher and Sweeney (1998). That is, in our study (Fisher and Sweeney's study), 30.4 (25.9) percent of subjects are liberals, 26.1 (27.7) percent are moderates and 43.5 (46.4) percent are conservatives. 
Using the method of groupings advocated by Fisher and Sweeney, Panel B of Table 5 provides two sets of average scores for each manipulation of political perspective for our data. There are no significant differences between DIT scores based on self-presentation and DIT scores based on instructions to respond from either an "extremely liberal" or "extremely conservative" perspective. Accordingly, as indicated in Panel B of Table 5, the results of our tests are very robust; none of our findings change from altering the cutoff points we used for our groupings to those Fisher and Sweeney advocated.

The findings of our research combined with the HERI and NES data suggest that a better approximation would be obtained from a seven-point scale by using a political split of 1 and 2 for liberals, 3 to 5 for moderates, and 6 and 7 for conservatives rather than Fisher and Sweeney's groupings of 1 to 3 for conservative, 4 for moderates, and 5 to 7 for conservatives. Our results also reinforce Siegel and Castellan's (1988: 24) basic requirement for subclass equivalence in nominal classifications.

\section{CONCLUSIONS}

Because we find differences in subjects' classification according to scale used (i.e., seven- versus nine-point), our results call into question the appropriateness of using a seven-point, unevenly apportioned scale for classifying subjects as political liberals, moderates or conservatives. Further, because we find 
fundamental differences between political orientation classifications among subjects in our sample and Fisher and Sweeney's (1998), our results reinforce the need to replicate Fisher and Sweeney's $(1998,2001)$ studies and re-assess the robustness of the hypotheses they proposed.

Rather than affirming the validity of the DIT, our research questions the methodology Fisher and Sweeney used. Thus, while our results do not indicate that political orientation can affect DIT P scores, we believe that a single study cannot stand alone. We do not believe that Fisher and Sweeney employed a valid procedure for categorizing their sample as political liberals, moderates or conservatives (c.f., Siegel and Castellan, 1988). Consequently, our study suggests that further empirical research is necessary.

With respect to the differences between our study and those of Sweeney and Fisher, other researchers should remember three points. First, all of Fisher and Sweeney's/Sweeney and Fisher's studies use samples from two Midwestern universities. Both of these schools are public universities affiliated with their respective states. In the current study, our sample comes from three private universities located in the Northeast. A limitation in most behavioral studies is that the samples represent only a small portion of the population and therefore, the results may not generalize (i.e., there is some degree of self-selection bias in university populations). Our results indicate that, even though Sweeney and 
Fisher/Fisher and Sweeney have several studies indicating the same results, their findings are not generalizable to a different sample.

Second, when one segments a sample into parts for analysis, the choice of segments may drive the results. To avoid this possibility, most research methodologies perform additional data analysis segmenting their samples differently to test how robust their findings are (i.e., our use of the groupings advocated by Fisher and Sweeney to reinforce our findings with respect to hypotheses $2 \mathrm{~b}$ and $2 \mathrm{c}$, as shown in Panel B of Table 5). This is especially critical when there are differences in the data and by national samples (e.g., NES and HERI). The only way for Fisher and Sweeney to address this concern in their four studies is to expand their moderate range to include individuals whose political orientations are from three to five and limiting their liberal (conservative) range to those indicating political orientations of one and two (six and seven). Such a test would enhance the analysis of their data.

Finally, a simple regression analysis should indicate if scores on the DIT are dependent on political orientation. Thus, if a liberal political orientation accounts for a high DIT P score, in our (Sweeney and Fisher's, 1998) data, liberals indicating a political orientation of one should have the highest DIT P score, while conservatives indicating a political orientation of nine (seven) should have the lowest average score on the DIT. Indeed, although Rest et al. (1999: 83) indicate that political orientation explains a large percentage of variance in DIT 


\section{Political Ideology On DIT Scores}

scores (i.e., over 40 percent of the variance in some studies), data in this study as well as in Bailey et al. (2002) refute this premise. In this study, we can attribute less than one percent of the variation in DIT P scores to political orientation. In Bailey et al.'s (2002: 9) study, the authors attribute less than five percent of the variation in DIT P scores to political orientation.

Two limitations are present in this research. First, the research sample includes students from three private schools. While this sample includes one more school than Fisher and Sweeney's sample, the robustness of our findings may be restricted and may not be applicable to the entire population of accounting students. Second, the research assumes that Rest's Defining Issues Test is capable of measuring moral reasoning. 


\section{APPENDIX A}

\section{Political Attitudes Survey: Experiment One}

a. Some people feel that the federal government in Washington should see to it that every person has a job and good standard of living. Others think that the government should just let each person get ahead on his/her own. And of course, other people have opinions somewhere in between. Where would you place yourself on this scale?

Government sees

Government lets each

to job and good person get ahead on

standard of living

his/her own

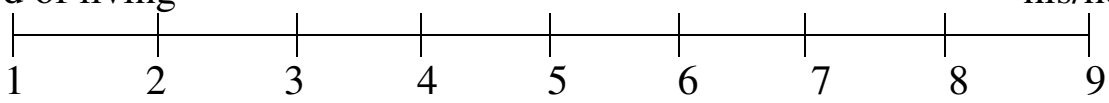

b. There is much concern about the rapid rise in medical and hospital costs.

Some feel that there should be a government insurance plan that would cover all medical and hospital expenses. Others feel that medical expenses should be paid by individuals and through private insurance like Blue Cross. Where would you place yourself?

Government insurance plan

Private

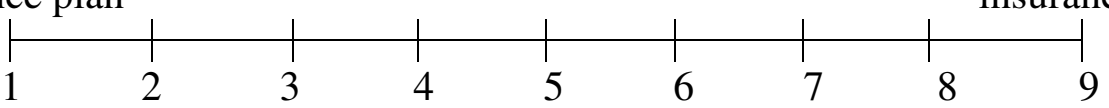

c. Some feel that the federal government in Washington should make every effort to improve the social and economic position of African-Americans and other minority groups. Others feel that the government should not make any special effort to help minorities because they should help themselves. Where would you place yourself on this scale?

Government should help

minority groups

Minority groups should

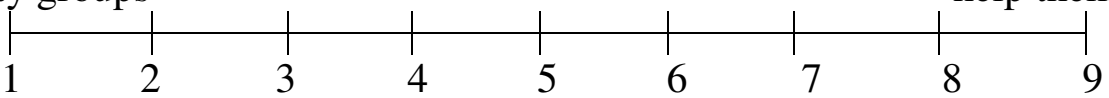

d. Concerning important political and social issues, where would you place yourself on the following NINE-POINT scale?

Extremely liberal

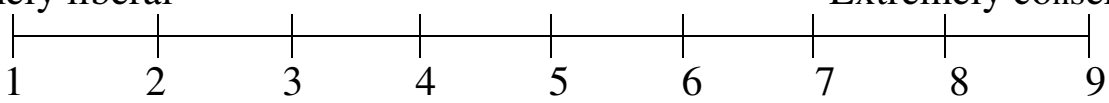




\section{APPENDIX B}

\section{Political Attitudes Survey: Experiment Two}

a. Some people feel that the federal government in Washington should see to it that every person has a job and good standard of living. Others think that the government should just let each person get ahead on his/her own. And of course, other people have opinions somewhere in between. Where would you place yourself on this scale?

Government sees

Government lets each

to job and good person get ahead on

standard of living

his/her own

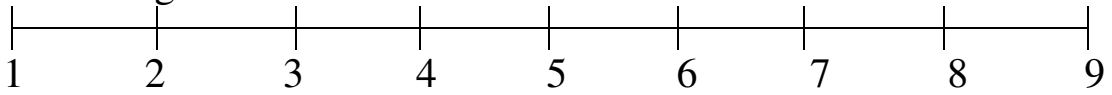

b. There is much concern about the rapid rise in medical and hospital costs. Some feel that there should be a government insurance plan that would cover all medical and hospital expenses. Others feel that medical expenses should be paid by individuals and through private insurance like Blue Cross. Where would you place yourself?

Government insurance plan

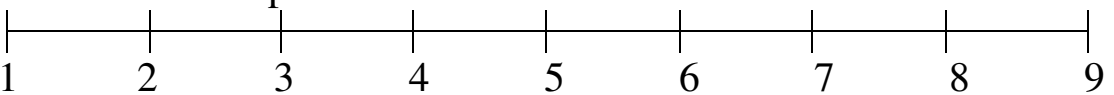

c. Some feel that the federal government in Washington should make every effort to improve the social and economic position of African-Americans and other minority groups. Others feel that the government should not make any special effort to help minorities because they should help themselves. Where would you place yourself on this scale?

Government should help minority groups

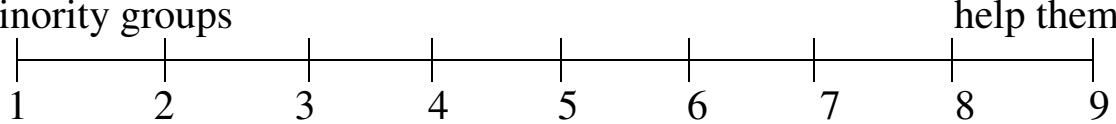

d. There has been much discussion concerning abortion during recent years. Which of the following opinions best agrees with your view?

1. Abortion should never be permitted.

2. Abortion should be permitted only if the life and health of the woman is in danger.

3. Abortion should be permitted if, due to personal reasons, the woman would have difficulty in caring for the child.

4. Abortion should never be forbidden, since one should not require a woman to have a child she doesn't want. 


\section{NOTES}

1. While all three authors contributed equally to this research, the lead and second authors are involved in several research projects and alternate lead author responsibilities.

2. Since Sweeney and Fisher (1999) replicates Fisher and Sweeney (1998) with nearly identical hypotheses and results, for ease of exposition, the remainder of our paper focuses on the 1998 study (i.e., Fisher and Sweeney, 1998).

3. The political orientation scale on the DIT2 approximates the HERI (2002) five-point scale: (1) Very liberal, (2) Somewhat liberal, (3) Neither liberal nor conservative, (4) Somewhat conservative, and (5) Very Conservative (emphasis added).

4. Item $d$ of the NES survey has only four points compared to the nine for the other four questions. To provide equal weighting, we scored choice one as 1.0, choice two as 3.67 , choice three as 6.33 , and choice four as 9.0. Note also that while the correlation between participants' self-indicated political orientation and their responses to the five issues drawn from the NES in Experiment Two (.464) is higher than the correlation between participants' self-indicated political orientation and their responses to the three issues drawn from the NES we previously reported for Experiment One (.387), both correlations are highly significant (i.e., $\mathrm{p}<.001$ in both cases). Further, the sum of the five items used 
in this experiment alone correlates $(.896, \mathrm{p}<.001)$ with the sum of the first three items, which were used in both experiments.

5. The reason we use the 1979 version of the DIT is because all of the accounting research using the DIT prior to 2000 used this version. By calling into question the 1979 version of the DIT, Fisher and Sweeney also challenge the validity of the results of over ten years of accounting research.

6. We also note that the manipulation affected politically liberal individuals who received instructions to answer from an extremely liberal perspective. That is, average P Score in the self-presentation condition, 25.43, increased by fivepoints to 30.43 when liberals responded from an extremely liberal perspective; however, this difference was not significant. 


\section{REFERENCES}

Alozie, C. (1976). An Analysis of the Interrelationship of Two Measures Used in the Measurement of Moral Judgment Development: The Kohlberg Moral Judgment Interview and the Rest Defining Issues Test, Unpublished doctoral dissertation, University of Minnesota.

Bailey, C. D., Phillips, T. J., Jr. and Scofield, S. B. (2002). The Impact of Education on the Moral Reasoning Abilities of Auditing Students, presented at the $7^{\text {th }}$ Annual Symposium on Ethics in Accounting in San Antonio, Texas.

Bernardi, R. A. (1991). Fraud Detection: An Experiment Testing Differences in Perceived Client Integrity and Competence, Individual Auditor Cognitive Style and Experience, and Accounting Firms, Unpublished doctoral dissertation, Union College, Schenectady, NY.

Bernardi, R. A. and D. Arnold. (1997). An Examination of Moral Development by Gender, Staff Level, and Firms within Public Accounting, Contemporary Accounting Research Fall, 653-668.

Davison, M. and Robbins, S. (1978). The Reliability and Validity of Objective Indices of Moral Development, Applied Psychological Measurement 2 (3), 391-403.

Dortzbach, J. (1975). Moral Judgment and Perceived Locus of Control: A CrossSectional Developmental Study of Adults Aged 25-74, Unpublished doctoral dissertation, University of Oregon.

Emler, N. Renwick, S. and Malone, B. (1983). The Relationship between Moral Reasoning and Political Orientation, Journal of Personality and Social Psychology 45 (5), 1073-1080.

Fisher, D. and Sweeney, J. (1998). The Relationship between Political Attitudes and Moral Judgment: Examining the Validity of the Defining Issues Test, Journal of Business Ethics 17 (8), 905-916. 
Fisher, D. and Sweeney, J. (2001). The Influence of Political Ideology on DIT P Scores: Implications for Accounting Ethics Research. Presented at the American Accounting Association's Sixth Symposium on Ethics Research in Accounting in Atlanta, GA.

Frankfort-Nachmias, C. and Nachmias, D. (1992). Research Methods in the Social Sciences (4th ed.). New York: St. Martin's Press.

Gilligan, C. (1982). In a Different Voice. Cambridge, MA: Harvard University Press.

Higher Education Research Institute (HERI). (2002). Freshmen Survey Results, www.gseis.ucla.edu/ heri/cirp-freshmen-survey_results.htm

Kohlberg, L. (1958). The Development of Models of Moral Thinking and Choice in the Years Ten to Sixteen, Unpublished doctoral dissertation, University of Chicago.

Kohlberg, L. (1969). Stages and sequences: The Cognitive Developmental Approach to Socialization, In D. Goslin, ed., Handbook of Socialization Theory and Research. Chicago: Rand McNally.

Kohlberg, L. (1973). The Claim to Moral Adequacy of a Highest Stage of Moral Judgment, Journal of Philosophy 70 (Oct), 630-646.

Louwers, T., Ponemon, L. A. and Radke, R. (1997). Examining Accountants' Ethical Behavior: A Review and Implications for Future Research. In V. Arnold and S. Sutton, eds. Behavioral Accounting Research: Foundations and Frontiers. Sarasota, FL: American Accounting Association.

Massey, D. W. (1997). An Investigation into the Assessment of Auditors Professional Moral Abilities and Their Improvement through the Use of Task-properties Feedback, Unpublished doctoral dissertation, University of Connecticut, Storrs, CT.

McGeorge, C. (1975). The Susceptibility to Faking of the Defining Issues Test of Moral Development, Developmental Psychology 11, 108.

National Election Studies (NES). (2002). The NES Guide to Public Opinion and Electoral Behavior, (http://www.umic.edu/ nesguide/nesguide.htm). Ann Arbor, MI: University of Michigan, Center for Political Studies [producer and distributor]. 
The Influence of Political Ideology in DIT Scores

Ponemon, L. A. (1988). A Cognitive-Developmental Approach to the Analysis of Certified Public Accountants Ethical Judgments, Unpublished doctoral dissertation, Union College, Schenectady, NY.

Ponemon, L. A. and D. Gabhart. (1993). Ethical Reasoning in Accounting and Auditing, Vancouver, Canadian Certified General Accountants' Research Foundation.

Rest, J. R. (1979). Defining Issues Test, Center for the Study of Ethical Development, Minneapolis, MN: University of Minnesota Press.

Rest, J. R. (1986). Moral Development: Advances in Research and Theory, New York, Praeger.

Rest, J. R. (1987). Guide for the Defining Issues Test. Minneapolis, MN: Center for the Study of Ethical Development.

Rest, J., Narváez, D., Bebeau, M. J. and Thoma, S. J. (1999). Postconventional Moral Thinking: A Neo-Kohlbergian Approach, Mahwah, NJ: Erlbaum.

Rest, J. R., Cooper, D., Coder, R., Masanz, J. and Anderson, D. (1974). Judging Important Issues in Moral Dilemmas - An Objective Test of Development, Developmental Psychology 10 (4), 491-501.

Rest, J. R. and Narváez, D. (1994). Moral Development in the Professions. Hillsdale, NJ: Lawrence Erlbaum Associates.

Siegel, S. and Castellan, N., Jr. (1988). Nonparametric Statistics for the Behavioral Sciences. NY: McGraw-Hill, Inc.

Sweeney, J. and Fisher, D. (1999). Politics, Faking, and Self-Presentation: How Valid is the $P$ Score of the Defining Issues Test, Research on Accounting Ethics 5, 51-75.

Sweeney, J. and Fisher, D. (1998). An Examination of the Validity of a New Measure of Moral Judgment, Behavioral Research on Accounting 10, 139158. 
Thorne, L. (1997). The Influence of Social Interaction on Auditors' Moral Reasoning, Unpublished doctoral dissertation, McGill University, Montreal, Canada.

Thornton, J. (2000). Challenges to the Defining Issues Test: A New Perspective on Accountants' Moral Development, Research on Accounting Ethics 7, 225-252. 
TABLE 1. Seven- Versus Nine-Point Scale Distributions ${ }^{1,2}$

\begin{tabular}{|c|c|c|c|c|c|c|c|c|c|}
\hline & \multicolumn{3}{|c|}{ Liberal } & \multirow{2}{*}{$\begin{array}{c}\text { Moderate } \\
\text { Four }\end{array}$} & \multicolumn{3}{|c|}{ Conservative } & \multirow{2}{*}{\multicolumn{2}{|c|}{ Total }} \\
\hline & One & Two & Three & & Five & Six & Seven & & \\
\hline One & 6 & 1 & 1 & & & & & 87 & \\
\hline Two & 3 & 21 & 3 & & & & & 27 & 122 \\
\hline Three & 2 & 35 & 43 & 7 & & & & 87 & \\
\hline Four & & $\underline{\underline{3}}$ & $\underline{\underline{74}}$ & 22 & $\underline{1}$ & & & 100 & \\
\hline Five & & $\underline{\underline{3}}$ & $\underline{\underline{13}}$ & 155 & $\underline{14}$ & & & 185 & 366 \\
\hline Six & & & $\underline{\underline{1}}$ & 20 & $\underline{59}$ & $\underline{1}$ & & 81 & \\
\hline Seven & & & & 3 & 23 & 27 & & 53 & \\
\hline Eight & & & & & 2 & 14 & 1 & 17 & 81 \\
\hline Nine & & & & & & & 11 & 11 & \\
\hline Total & 11 & 63 & 135 & 207 & 99 & 42 & 12 & 569 & \\
\hline & & 209 & & 207 & & 153 & & & \\
\hline
\end{tabular}

${ }^{\mathrm{T}}$ The data represent the number of individuals.

${ }^{2}$ Shaded areas indicate classification agreement between the two scales.

${ }^{3}$ Single (double) underlined data are the individuals who switched from a Conservative (Liberal) political orientation on a seven-point scale to a Moderate orientation on the nine point scale. 
TABLE 2. Contingency Tables for Seven- and Nine-Point Scales ${ }^{1,2}$ $x^{2}$ Liberal Moderate Conservative (p-value)

H1: Nine-Point Scale

Observed (Table 1, 9-pt)

Expected (Table 1, 7-pt)

$21.4 \%$

$64.3 \%$

29.5

$(.001)$

$\underline{\text { Seven-Point Scales }}$

Observed (Table 1, 7-pt)

$36.7 \%$

$36.4 \%$

$\left.\begin{array}{l}26.9 \% \\ 46.4 \%\end{array}\right\} \begin{gathered}16.2 \\ (.001)\end{gathered}$

Expected (F\&S, 7-pt)

$25.9 \%$

$27.7 \%$

${ }^{1}$ All observed frequencies were computed using the Table 1 data. For instance, the observed frequency of $21.4 \%(36.7 \%)$ for the nine-point scale (seven-point scale) includes the 122 (209) individuals who identified themselves as having a liberal orientation (points 1-to-3 on either scale) divided by the total sample of 569.

${ }^{2}$ Expected frequencies for the nine-point scale were computed from our sevenpoint data appearing in Table 1. Expected frequencies for the seven-point scales are from Fisher and Sweeney's seven-point data (1998: 909). Percentage calculations are the same as in note 1 . 
TABLE 3. Comparison of Study Data with National Data

\begin{tabular}{|c|c|c|c|c|c|c|c|}
\hline $\begin{array}{l}\text { NES } \\
\text { Categories }\end{array}$ & $\begin{array}{l}\text { NES } \\
\text { Data }\end{array}$ & $\begin{array}{l}\text { NES } \\
\text { M1 }\end{array}$ & $\begin{array}{l}\text { F\&S } \\
\text { Data }\end{array}$ & $\begin{array}{l}\text { NES } \\
\text { M2 }\end{array}$ & $\begin{array}{l}\text { Our } \\
\text { Data }\end{array}$ & $\begin{array}{l}\text { HERI } \\
\text { Data }\end{array}$ & $\begin{array}{l}\text { HERI } \\
\text { Categories }\end{array}$ \\
\hline Extremely Liberal & 2.2 & & & 123 & 214 & 247 & Far Left \\
\hline Liberal & 10.1 & -24.8 & 25.9 & & & & Liberal \\
\hline Slightly Liberal & 12.6 & & & & & & $\int$ \\
\hline Moderate & 34.4 & 34.4 & 27.7 & 66.4 & 64.3 & 54.6 & Moderate \\
\hline Slightly Conservative & 19.4 & & & & & & \\
\hline Conservative & 18.1 & 40.7 & 46.4 & 213 & 140 & 207 & $\int$ Conservative \\
\hline $\begin{array}{l}\text { Extremely } \\
\text { Conservative }\end{array}$ & 3.2 & & & & & & Far Right \\
\hline
\end{tabular}

\section{Legend:}

Method 1 (M1) All Liberal, only Moderate, all Conservative (7-point scale)

Fisher \& Sweeney All Liberal, only Moderate, all Conservative (i.e., same as M1) (7-point Scale)

Method 2 (M2) Liberal $\quad$ Extremely Liberal + Liberal

(7-point scale) Moderate Slightly Liberal, Moderate + Slightly Conservative

Conservative Extremely Conservative + Conservative

$\begin{array}{cll}\text { Our Data } & \text { Liberal } & \text { 1-to-3 on the 9-point scale } \\ \text { (9-point scale) } & \text { Moderate } & \text { 4-to-6 on the 9-point scale } \\ & \text { Conservative } & \text { 7-to-9 on the 9-point scale }\end{array}$

$\begin{array}{cll}\text { HERI Data } & \text { Liberal } & \text { Far Left + Liberal } \\ \text { (5-point Scale) } & \text { Moderate } & \text { Moderate } \\ & \text { Conservative } & \text { Far Right + Conservative }\end{array}$


TABLE 4. DIT Scores ${ }^{1}$ by Self-Defined Political Orientations

\begin{tabular}{|c|c|c|c|c|c|}
\hline & Stage 3 & Stage 4 & Stage 5 & Stage 6 & P Score \\
\hline \multicolumn{6}{|c|}{ Liberals $(n=22)$} \\
\hline Mean & 22.71 & 35.82 & 18.59 & 5.99 & 24.58 \\
\hline \multicolumn{6}{|c|}{ Moderates $(n=58)$} \\
\hline Mean & 21.81 & 32.03 & 25.10 & 3.13 & 28.23 \\
\hline \multicolumn{6}{|c|}{ Conservatives $(n=35)$} \\
\hline Mean & 19.73 & 33.85 & 23.67 & 3.06 & 26.73 \\
\hline \multicolumn{6}{|c|}{ Overall $(n=115)$} \\
\hline Mean & 21.45 & 32.76 & 23.73 & 3.64 & 27.37 \\
\hline \multicolumn{6}{|c|}{ Rest's College $^{2}(n=270)$} \\
\hline Mean & 14.33 & 28.35 & 35.03 & 8.16 & 43.19 \\
\hline \multicolumn{6}{|c|}{ Fisher \& Sweeney $^{3}(n=112)$} \\
\hline Mean & 13.33 & 36.63 & 34.15 & 4.01 & 38.16 \\
\hline \multicolumn{6}{|c|}{$\begin{array}{l}2 \text { All data 1s standardized data (1.e., equivalent scoring to P scores) } \\
{ }^{2} \text { Rest's data are from the Guide for the Defining Issues Test (1987: 3-13) }\end{array}$} \\
\hline
\end{tabular}


TABLE 5. Effects of Political Perspective on DIT Scores

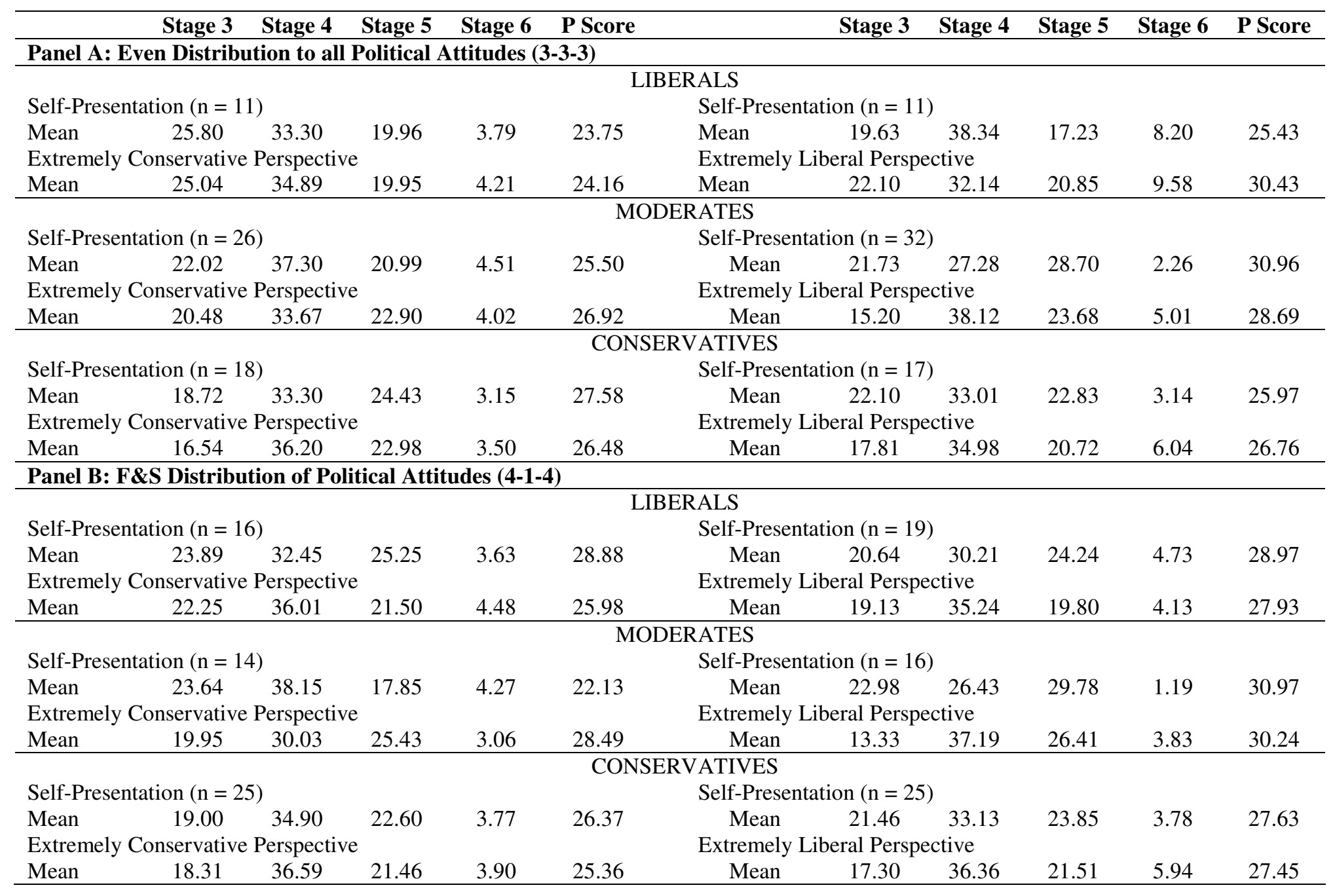

